\title{
Theoretical calculation of uv-vis, ir spectra and reactivity properties of tamoxifen drug: a methodology comparison
}

\begin{abstract}
Some theoretical properties were analyzed and compared with the experimental data for Tamoxifen molecule, a drug commonly used as complementary therapy for breast cancer. The molecular structure and some chemical reactivity parameters were calculated through Density Functional Theory using different functionals, including B3LYP, PBE0, PBEPBE, TPSS, TPSSh and the M05 and M06 density functionals of Minnesota family, all of them combined with a 6-31G (d) basis set. The theoretical IR and ultraviolet-visible (V-Vis) spectra were compared with experimental data. Reactivity parameters are of great importance in the pharmacological testing. For this reason, a correlation between the different chemical models was carried out using the electron affinity and ionization potential calculations. According to the outcomes, the methodology that had a better correlation with the experimental data is M06/6-31G (d).
\end{abstract}

Keywords: DFT, tamoxifen, vibrational analysis
Volume I Issue 3 - 2017

\section{Linda-Lucila Landeros-Martinez, Daniel Glossman-Mitnik, Erasmo Orrantia-Borunda, Norma Flores-Holguin \\ Advanced Materials Research Center (CIMAV), Mexico}

Correspondence: Norma Flores-Holguin, Advanced Materials Research Center (CIMAV), Miguel de Cervantes I20, CP 31 |36, Chihuahua, Chih, Mexico, Tel 52-614-4394805, Email norma.flores@cimav.edu.mx

Received: March 27, 2017 | Published: August 22, 2017
Abbreviations: TAM, tamoxifen; DFT, density functional theory; SERM, selective estrogen receptor modulator; TD-DFT, time-dependent density functional theory; HOMO, highest occupied molecular orbital; LUMO, lowest unoccupied molecular orbital; EA, electron affinity; I, ionization potential; $\eta$, chemical hardness; $\chi$, electronegativity; $\omega$, electrophilicity index; $\mu$, chemical potential

\section{Introduction}

Tamoxifen[(Z)-2-(4-(1,2-Diphenyl-1-butenyl)-phenoxy)-N,Ndimethylethanamine] (TAM) has been prescribed to treat patients with breast cancer. ${ }^{1}$ TAM is a selective estrogen receptor modulator (SERM). ${ }^{2,3}$ This drug acts as anti-estrogen in breast tissue by interfering with the activity of estrogen: the female sex hormone that promotes the growth of cancer cells in the breast. ${ }^{4-6}$

On the other hand, it is known that theoretical studies of geometrical, electronic, chemical and spectral properties of drugs are very important as they provide information if the drug has a change in orientation (conformational), ${ }^{7}$ its reactive behavior, ${ }^{8}$ the structure-activity relationship ${ }^{9,10}$ and determine the way the molecule interacts with other species. ${ }^{11}$

Some authors have studied the structure-activity relationship (QSAR) of TAM,${ }^{12}$ which showed that a small difference in the chemical structure can alter the pharmacological activity. ${ }^{13}$ In recent years, the density functional theory (DFT) calculations reported to provide excellent vibrational frequencies of organic compounds, ${ }^{14}$ in spectroscopic properties ${ }^{15}$ and reactivity descriptors of organic and inorganic compounds. ${ }^{16}$ Also, theoretical studies based on quantum calculations through BLYP/6-31G $+(\mathrm{d}, \mathrm{p})$ and B3LYP/6-31G $+(\mathrm{d}, \mathrm{p})$ have achieved optimized structures in good agreement with $\mathrm{X}$-ray experimental geometries, and were thus used to investigate the flip-flop process of the TAM propeller and derivatives. ${ }^{17}$ However, it is important to find a suitable methodology that describes the vibrational properties of TAM, since this will lead to a reliable optimized molecular structure. Besides the detailed knowledge about a structure of drugs, spectra and other properties is necessary for better understanding their chemical and biological. ${ }^{18}$

The calculation of the vibrational frequencies is a very good aid for the assignment of the IR spectra. ${ }^{19}$ UV-Vis spectrophotometry is one of the most frequently employed techniques in pharmaceutical analysis. It involves measuring the amount of ultraviolet or visible radiation absorbed by a substance in solution. ${ }^{20}$ Furthermore, evaluation of UV-Vis may be necessary in the following circumstances: changes in the synthesis of the drug substance; changes in the composition of the finished product and changes in the analytical procedure. ${ }^{20}$ The wavelength of maximum absorption $\left(\lambda_{\max }\right)$ is normally selected.

Moreover, to know the absorption bands of the UV-vis spectrum is very import considering because the quantification of the medicinal substance can be measured by $\lambda_{\text {max }}{ }^{20}$ This spectrum also shows the frontier orbital transitions, variations that may lead to the formation of bonds between different atoms. These data are of significant interest for future investigations on the use of carrier vehicles loaded with the drug Tamoxifen or its derivatives.

The main goal of this research was to validate the chemical model that best describes the electronic properties and chemical reactivity parameters of the TAM molecule. Hence, several density functional were selected to calculate the electronic properties, which were compared with experimental results. Thereby, eleven density functionals were evaluated using the $6-31 \mathrm{G}(\mathrm{d})$ basis set, reported by Pople et al. ${ }^{21}$ Some of the defined methodologies were chosen by the experience of previous studies of our research group such as: PBE0 in megazol drug ${ }^{22}$ and chemical reactivity of pyrrole derivatives; ${ }^{23}$ B3LYP, M05 and M06 density functionals with Cyanidin molecules ${ }^{24}$ and 
the theoretical spectroscopic analysis of Riluzole, using FT-IR, FT-Raman and UV-Vis techniques were obtained with three functionals (B3LYP, MPWLYP and M06-2X) and 6-311++G(d,p) basis set having agreement between experimental and the calculated. ${ }^{25}$ According of the study reported by Soto-Rojo et al. ${ }^{26}$ the M06 functional presents the best alternative to obtain the UV-Vis spectra with good accuracy. ${ }^{26}$ The theoretical determination of chemical model for TAM can be very useful in the design and development of new and better drugs, allowing so that other researchers have the facility to use the chemical model in other derivatives of the drug tamoxifen without validate the chemical model.

\section{Computational details}

All calculations were performed using the Gaussian 09 software. ${ }^{27}$ The Density Functional Theory (DFT) was used, ${ }^{28-30}$ which has been proven to be a key method for drug design and specifically in the field of transition metals with medicinal applications, and has been successful in terms of accuracy and reliability. ${ }^{31}$ The used functionals were: Perdew, Burke and Ernzerhof GGA functional, PBE0;32 GGA hybrid functionals, Becke three parameter Lee, Yang, and Parr, B3LYP, ${ }^{33}$ and PBEPBE; ${ }^{34}$ Tao, Perdew, Staroverov, and Scuseria meta-GGA, TPSS; ${ }^{35}$ Truhlar and coworkers meta-GGA local functional M06-L; ${ }^{26}$ and hybrid meta-GGA functionals M05-2X, ${ }^{36,37}$ M05, ${ }^{38,39}$ M06, ${ }^{36,40}$ M06-2X, ${ }^{36}$ M06-HF, ${ }^{41}$ and TPSSh, ${ }^{35}$ functionals that have different percentage of Hartree-Fock. These functionals were combined with Pople basis set $6-31 \mathrm{G}(\mathrm{d})^{21}$ for the geometrical optimizations, followed by a frequency calculation to confirm that the structure is at the minimum energy state. The theoretical Infrared spectra (IR) were also plotted with the results obtained by the different chemical model frequency calculations and compared with the experimental IR spectrum.

Ultraviolet-visible spectra (UV-Vis) were calculated by solving the time-dependent density functional theory (TD-DFT) equations ${ }^{42-44}$ approach and analyzed through the SWizard program; ${ }^{45}$ theoretical UV-Vis spectra were obtained with different chemical model in the presence of methanol as solvent, using the conductor-like polarizable continuum model $(\mathrm{CPCM})^{46}$ which defines the cavities as envelopes of spheres centered on atoms or atomic groups. Inside the cavity the dielectric constant is the same as in vacuum, outside it takes the value of the desired solvent; ${ }^{47}$ the equations were solved for 20 exited states.

The conceptual aspect of the density functional method has been amply used to understand the chemical reactivity, to define a set of chemical concepts such as the electron affinity (EA), ${ }^{48,49}$ ionization potential (I), ${ }^{48,49}$ chemical hardness $(\eta),{ }^{50}$ electronegativity $(\chi),{ }^{51,52}$ electrophilicity index $(\omega)^{53}$ and chemical potential $(\mu),{ }^{53}$ which are linked to their electronic structure and chemical reactivity. There are different ways to calculate the reactivity parameters. One formulations consists in calculate the ionization potential and electron affinity as the negative of the HOMO and LUMO energy respectively. It is called Koopmans' theorem. This approximation is widely used with good results..$^{54,55}$ In the research group of the authors is commonly to calculate with the second approximation, it uses the energy difference between the precursor molecule and the species formed by the adding or removing of an electron. It is the energy difference approximation and considers the energy $(E)$ as a function of the number of electrons $(\mathrm{N})$. The equations of the chemical reactivity calculated by this method are shown in Table 1.
Table I Equations of global reactivity

$E A=E(N)-E(N+1)$
$I=E(N-1)-E(N)$
$\eta=\frac{(I-E A)}{2}$
$\chi=\frac{(I+A E)}{2}$
$\omega=\frac{\mu^{2}}{2 \eta}$
$\mu=-\chi$

\section{Results and discussion}

\section{Geometry optimization and Calculated IR spectra}

The TAM structure was optimized in gas phase with all density functionals mentioned above, followed by a frequency calculation to confirm that the molecule has a minimum energy conformation, allowing to obtain the theoretical IR spectra, which were compared with experimental results, ${ }^{56}$ to choose a reliable functional. Figure 1 shows the optimized TAM structure with M06/6-31G (d) methodology.

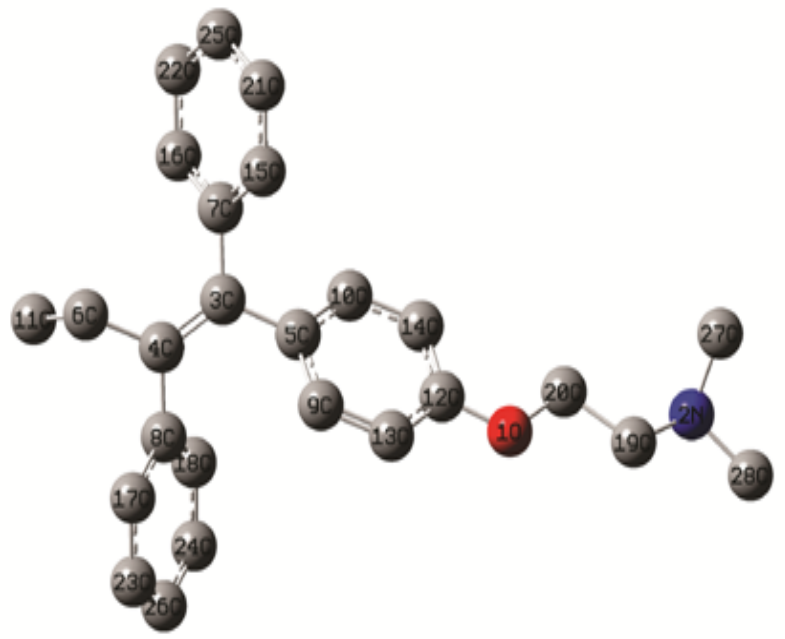

Figure I Optimized geometry of Tamoxifen obtained with M06/6-3IG (d).

The optimized structure of TAM shows a non-planar geometry because it has three dihedral angles: $\mathrm{C} 5-\mathrm{C} 3-\mathrm{C} 7-\mathrm{C} 16$ with a value of 126.40 degrees, the $\mathrm{C} 5-\mathrm{C} 4-\mathrm{C} 3-\mathrm{C} 8$ with -9.32 degrees, and $\mathrm{C} 3-\mathrm{C} 4-\mathrm{C}-$ 5-C6 with 171.69 degrees, and a dihedral angle at the opposite end of the molecule, which corresponds to the angle $\mathrm{C} 20-\mathrm{C} 19-\mathrm{N} 2-\mathrm{C} 27$ with a value of 69.86 degrees.

The theoretical IR spectra values obtained with the different chemical models were compared with the experimental FT-IR spectrum values. Some of the principal vibrations correspond to different func- 
tional groups, such as: Alkane $\mathrm{C}-\mathrm{H}$ stretching, Alkene $-\mathrm{C}=\mathrm{C}$ - stretching and $\mathrm{C}=\mathrm{C}$ ring stretching. The frequency values found for each functional are shown in Table 2. These data were analyzed and the chemical models that reproduce with the best accuracy the experimental data reported by Shivam, ${ }^{56}$ are M06/6-31G (d) and PBE0/6-31G (d). Figure $2 \& 3$ show the theoretical Tamoxifen IR spectra for M06/ 6-31G (d) and PBE0/6-31G (d) respectively.

\section{UV-Visible absorption spectra}

The maximum UV-Vis absorption spectra results for Tamoxifen were performed in the presence of solvent, under the same optimiza- tion conditions mentioned above. The calculated maximum absorption wavelengths $(\lambda \max )$, the oscillator strength $(f)$, and electronic transitions are shown in Table 3. According to the results obtained in the UV-Vis theoretical spectra the chemicals models that exhibit a better agreement, are M06/6-31G (d) with 27\% HF exchange underestimate the $\lambda_{\max }$ by $6 \mathrm{~nm}, \mathrm{PBE} / 6-31 \mathrm{G}(\mathrm{d})$ with $25 \% \mathrm{HF}$ exchange underestimate by $7.8 \mathrm{~nm}$ and M05/631G(d) with $25 \% \mathrm{HF}$ exchange underestimate with $1.8 \mathrm{~nm}$ in relation to the $298.2 \mathrm{~nm}$ maximum absorption wavelength experimental reported by Merey. ${ }^{57}$ Figure 4 shows the theoretical Tamoxifen UV-Vis spectra for M06, PBE0 and M05 all 6-31G (d) basis set.

Table 2 Comparison of the theoretical vibrations modes with experimental FT-IR spectrum of Tamoxifen

\begin{tabular}{|c|c|c|c|}
\hline & \multicolumn{3}{|l|}{ Vibrations } \\
\hline & Alkane C-H Stretching $\mathrm{cm}^{-1}$ & Alkene $-C=C$ - Stretching $\mathrm{cm}^{-1}$ & $\mathrm{C}=\mathrm{C}$ ring stretching \\
\hline Chemical model & \multicolumn{3}{|l|}{ Theoretical data } \\
\hline B3LYP/6-3IG(d) & 3029.13 & 1655.32 & 1542.14 \\
\hline M05/6-3IG(d) & 3008.68 & 1680.05 & 1480.29 \\
\hline M05-2X/6-3IG(d) & 3014.92 & 1726.33 & 1515.79 \\
\hline M06/6-3IG(d) & 2929.74 & 1690.54 & 1458.97 \\
\hline M06-2X/6-3IG(d) & 3061.26 & |722.7| & $|502.9|$ \\
\hline M06-L/6-3IG(d) & 2950.85 & 1655.47 & 1399.23 \\
\hline M06-HF/6-3IG(d) & 3032.25 & 1747.4 & 1519.65 \\
\hline PBE0/6-3।G(d) & 2967.06 & 1687.72 & 1496.96 \\
\hline PBEPBE/6-3।G(d) & 2957.05 & 1596.74 & 1513.66 \\
\hline TPSS/6-3IG(d) & 3037.74 & 1607.86 & 1515.4 \\
\hline TPSSh/6-3IG(d) & 3027.43 & 1640.92 & 1539.88 \\
\hline Experimental data ${ }^{48}$ & $2800-3000$ & $1700-1740$ & $1400-\mid 500$ \\
\hline
\end{tabular}

Table 3 Comparison of the wavelengths $\left(\lambda_{\max }\right)$, modes with experimental UV-Vis spectra of Tamoxifen calculated with different chemical model with the 6-3I (G) basis set

\begin{tabular}{llll}
\hline Chemical model & $\lambda_{\text {Max }}$ & $\boldsymbol{F}$ & Electronic transitions \\
\hline B3LYP & 310.58 & 0.4047 & $\mathrm{H}-0->\mathrm{L}+0(+98 \%)$ \\
M05 & $300.0 \mathrm{I}$ & 0.4507 & $\mathrm{H}-0->\mathrm{L}+0(+98 \%)$ \\
M05-2X & 274.3 & 0.578 & $\mathrm{H}-0->\mathrm{L}+0(+96 \%)$ \\
M06 & 304.54 & 0.4536 & $\mathrm{H}-0->\mathrm{L}+0(+98 \%)$ \\
M06-2X & 277.63 & 0.56 & $\mathrm{H}-0->\mathrm{L}+0(+96 \%)$ \\
M06-L & 358.4 & 0.2268 & $\mathrm{H}-0->\mathrm{L}+0(+75 \%) \mathrm{H}-\mathrm{I}->\mathrm{L}+0(2 \mathrm{l} \%)$ \\
M06-HF & 246.08 & 0.6775 & $\mathrm{H}-0->\mathrm{L}+0(+87 \%)$ \\
PBE0 & 306.07 & 0.448 & $\mathrm{H}-0->\mathrm{L}+0(+99 \%)$ \\
PBEPBE & 410.22 & 0.0124 & $\mathrm{H}-\mathrm{I}->\mathrm{L}+0(+74 \%) \mathrm{H}-0->\mathrm{L}+0(26 \%)$ \\
TPSS & 379.75 & 0.0295 & $\mathrm{H}-\mathrm{I}->\mathrm{L}+0(+80 \%) \mathrm{H}-0->\mathrm{L}+0(20 \%)$ \\
TPSSh & 333.76 & 0.3522 & $\mathrm{H}-0->\mathrm{L}+0(+97 \%)$ \\
Experimental data ${ }^{57}$ & 298.2 & & \\
\hline
\end{tabular}




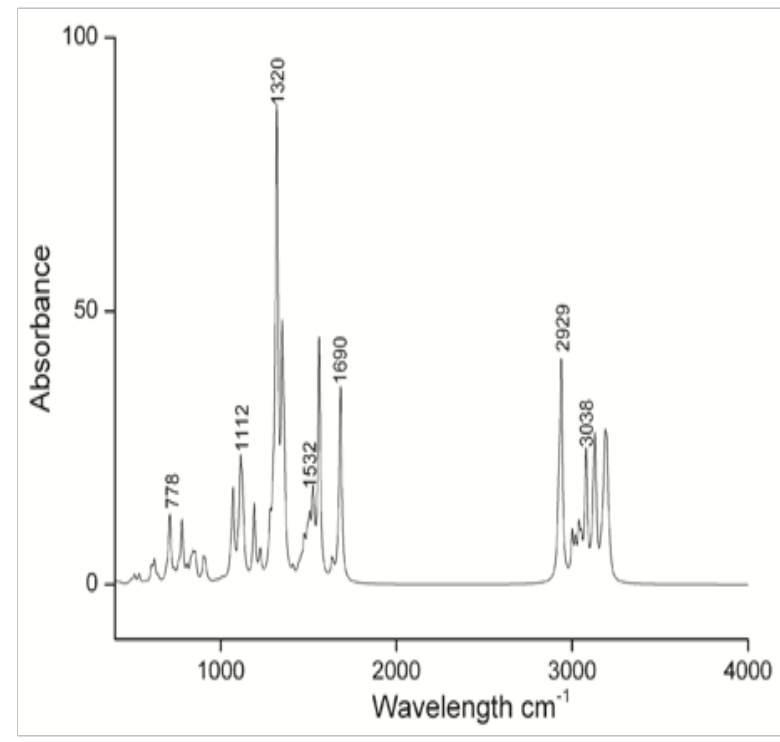

Figure 2 Theoretical IR spectra of Tamoxifen at the M06/6-3IG (d) level of calculation.

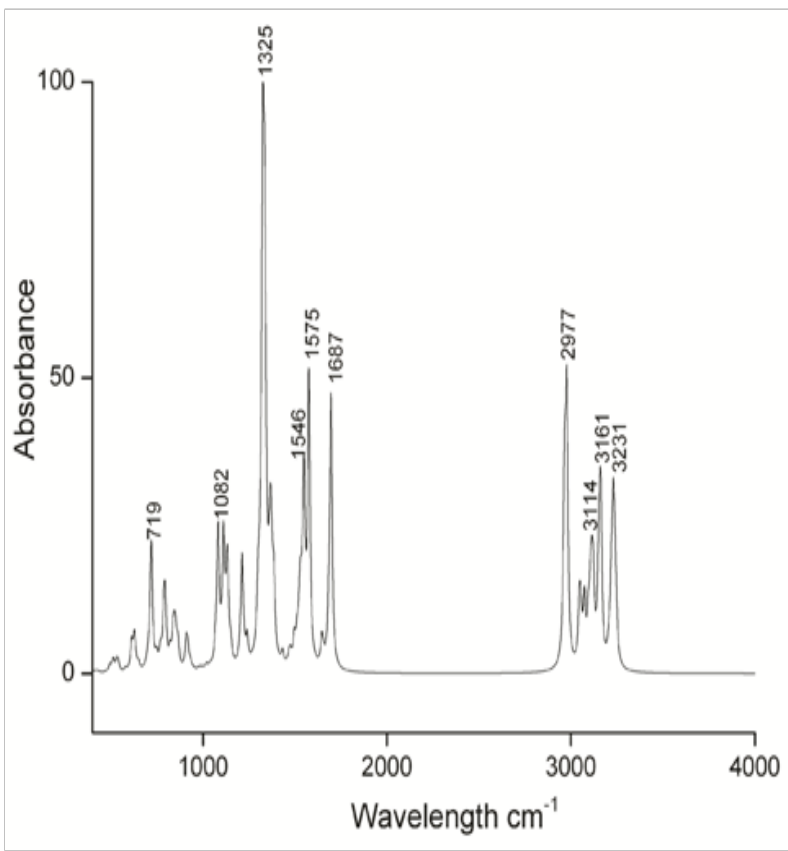

Figure 3 Theoretical IR spectra of Tamoxifen at the PBE0/6-3IG (d) level of calculation.

\section{Variables design and statistical analysis}

The chemical models M06/6-31G(d) and PBE/6-31G(d) reproduce adequately the experimental FT-IR spectrum and there is a has good approach to the experimental maximum absorption wavelength with M06/6-31G(d), PBE/6-31G(d) and M05/6-31G(d). Additionally, some reactivity parameters calculation were developed with the eleven functionals mentioned in the computational details section, with the aim to obtain variables that led to develop a statistical analysis of the methodologies and define the best one.

The developed calculated values are electron affinity (EA) and ionization potential (I) and the results are reported in Table 4. In this case all the electron affinity values are negative which means a resonance state or an accepted unbound electron according to Lewars, who states that the electron affinity has negative values when the accepted electron is ejected in microseconds. ${ }^{49}$

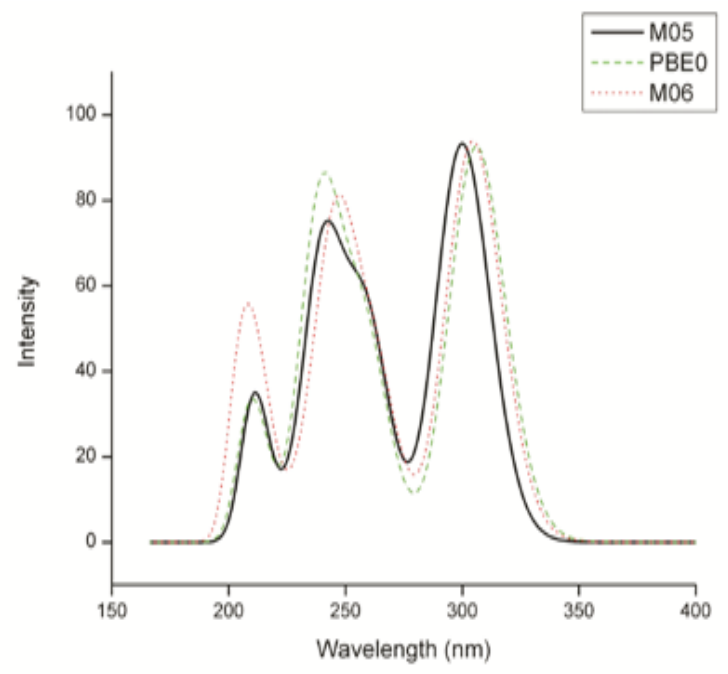

Figure 4 UV-Vis spectra of Tamoxifen calculated with M06/6-3IG (d), PBE0/6-3IG (d) and M05/6-3IG (d).

Table 4 lonization Potential and Electron Affinity of Tamoxifen with different functionals and 6-3IG (d) basis set

\begin{tabular}{lll}
\hline Functional & EA $(\mathbf{e V})$ & $\mathbf{I}(\mathbf{e V})$ \\
\hline B3LYP & -0.62 & 6.55 \\
M05 & -0.69 & 6.6 \\
M05-2X & -0.73 & 7.03 \\
M06 & -0.56 & 6.67 \\
M06-2X & -0.67 & 7.05 \\
M06-L & -0.4 & 18.8 \\
M06-HF & -0.91 & 7.56 \\
PBE0 & -0.56 & 6.65 \\
PBEPBE & -0.27 & 6.15 \\
TPSS & -0.38 & 6.15 \\
TPSSh & -0.48 & 6.36 \\
\hline
\end{tabular}

Regarding the ionization potential the values are in a range of 6.15 to $7.56 \mathrm{eV}$ with the exception of the value calculated with M06L, with a value of $18.8 \mathrm{eV}$. This can be attributed to the fact that $\mathrm{M} 06 \mathrm{~L}$ is the only local functional, with $0 \% \mathrm{HF}$ exchange, and considering that HF underestimates the ionization potential..$^{58}$ The only reactivity value found in Tamoxifen is the ionization potential, calculated with B3LYP by Garrido with a value of $6.49 \mathrm{eV} .{ }^{59}$ In this case, the results obtained with B3LYP, M05, M06 and PBE0 are the closest to the value calculated by Garrido.

A dispersion analysis was done with the results of the reactivity values obtained. It was eliminated the Ionization Potential calculated with M06-L/6-31G(d,) due to the different value compared with the others.

The mean value for the scattering data obtained is $-0.59 \mathrm{eV}$ and 
$6.70 \mathrm{eV}$ for EA and I respectively, while the median has values of $-0.59 \mathrm{eV}$ for EA and $6.63 \mathrm{eV}$ for I. These results allowed to calculate the standard deviation for the EA, which exhibits a value of 0.17 and 0.41 for I, and coefficients of variation of $28 \%$ and $6.3 \%$ respectively. These values represent excellent quality and low variability, ${ }^{60}$ and contribute to define the best model chemistry. The dispersion analysis results are in Figure 5 where the dash blue line represents the mean value for both, EA and I.

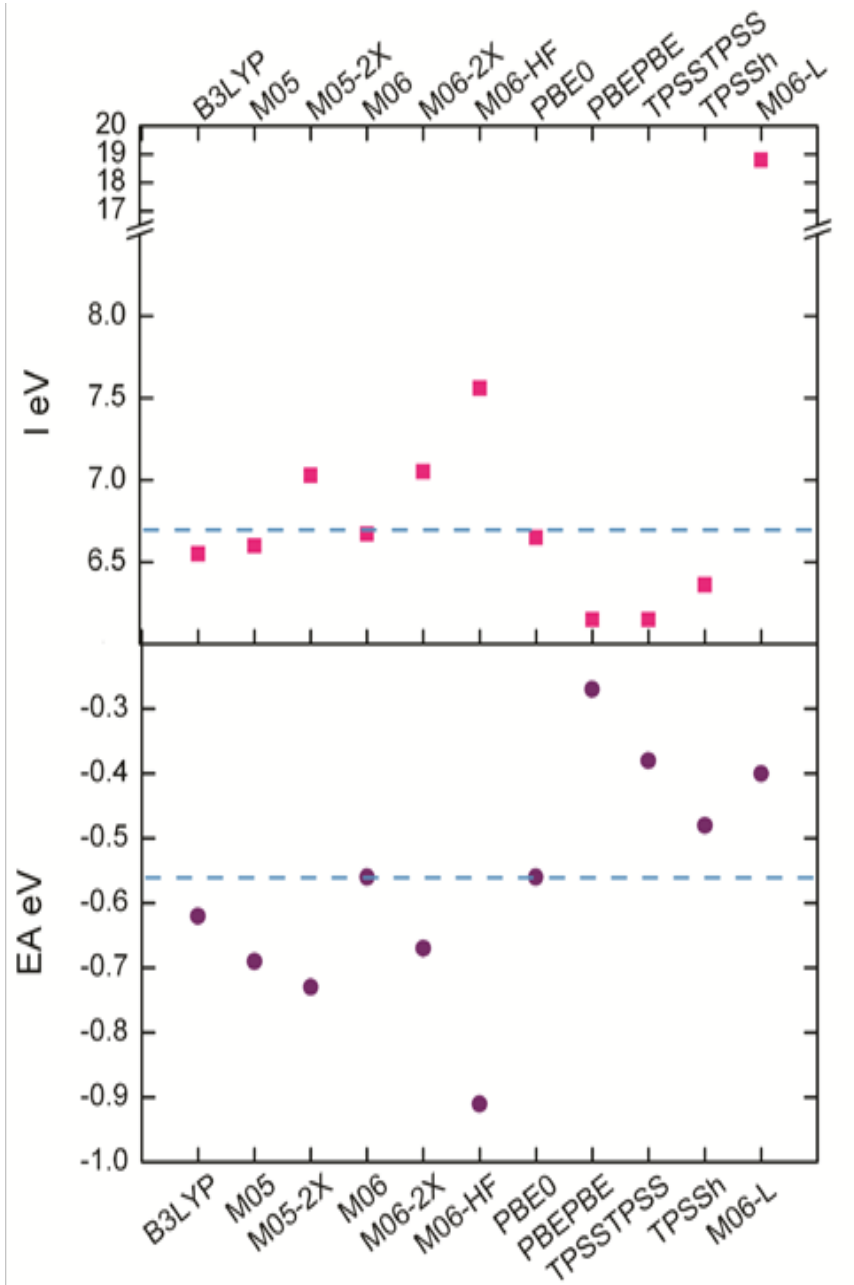

Figure 5 lonization potential and electron affinity for the model chemistries used in this study and the dispersion between the values.

The dispersion results show that there are two chemistry models with a first-rate approximation for being considered as the best methodology, M06/6-31G (d) and PBE0/6-31G (d). Considering that these two methodologies also have the best agreement with the experimental vibrations and the maximum absorption wavelengths shown above, a third statistical function, the z-score, was used to define the best methodology. This function indicates how many standard deviations an element is from the arithmetic mean. ${ }^{61}$

According to the results for z-score which are in Table 5, the typical value of the electron affinity scores (zAE) for M06/6-31G (d) and PBE0/6-31G (d) is the same, 0.18 . This indicates that both functionals have the same relative position to the mean value. However, typical ionization potential scores (zI) for the chemical models M06/6-31G (d), and PBE0/6-31G (d) are different, being -0.07 and -0.12 respecti- vely. Based on these results M06/6-31G (d) is the best approximation to calculate the Tamoxifen properties. We propose that the chemical model M06/6-31G (d) presents excellent approaches in this analysis.

Table $5 \mathrm{Z}$ score for ionization potential and electron affinity of M06/6-3 IG (d) and PBE0/6-3IG (d) methodologies

\begin{tabular}{lllll}
\hline Functional & AE $(\mathrm{eV})$ & $\mathbf{I}(\mathrm{eV})$ & zEA & zl \\
\hline M06 & -0.56 & 6.67 & 0.18 & -0.07 \\
PBE0 & -0.56 & 6.65 & 0.18 & -0.12
\end{tabular}

\section{Theoretical characterization of tamoxifen with M06/} 6-3 I G (d)

Once the methodology was defined, it was developed, the characterization of the molecule of Tamoxifen that included the structural parameters of minimal energy geometry and a comparison versus experimental bond lengths and angles. Also the electronic properties as electrostatic potential and reactivity parameters.

Structural parameters: We have compared the chemical model M06/6-31G (d) optimized geometry of TAM to the X-ray data ${ }^{62}$ (Table 6). The analysis the difference between the experimental and theoretical of bond lengths shows that in $\mathrm{C}-\mathrm{O}$ bond oscillate $0.054 \AA$, whereas $\mathrm{N}-\mathrm{C}$ the difference is $0.063 \AA$ and in $\mathrm{C}-\mathrm{C}$ is $0.063 \AA$. On the other hand in the bond angles the difference in the $\mathrm{C}-\mathrm{O}-\mathrm{C}$ has $7.53^{\circ}$, in $\mathrm{C}-\mathrm{N}-\mathrm{C} 1.29^{\circ}$, while alkene functional group with $0.512^{\circ}, 0.077^{\circ}$ and $-0.659^{\circ}$ in the bonds angles $\mathrm{C} 3-\mathrm{C} 5-\mathrm{C} 9, \mathrm{C} 3-\mathrm{C} 7-\mathrm{C} 15$ and $\mathrm{C} 4-\mathrm{C} 8-\mathrm{C} 18$ respectively. Therefore we have pointed out the good agreement of our theoretical results and the experimental ones.

Electrostatic potential surface: To evaluate the electronic distribution around Tamoxifen, the electrostatic potential surface (EPS) was plotted (Figure 6). The map show the negative potential sites that include electronegative atoms as well as the positive potential sites located around the hydrogen atoms. The main negative center includes the oxygen atom of the ether group and the nitrogen of the amine group. These atoms could be responsible of the interaction through the hydrogen bond with the active site in hormone receptors. This is because this type of bond involves a hydrogen atom that is attracted to a strongly electronegative atom, such as oxygen, fluorine, or nitrogen of a polar covalent bond, in the same or another molecule. ${ }^{63}$ The contour around TAM is found in the functional groups aryl, ethyl and ether of the drug; these regions most probably constitute the active site of the drug in chemical reactions. The EPS analysts agree with the frontier molecular orbitals study, where highest occupied molecular orbital (HOMO) and the lowest unoccupied molecular orbital (LUMO) are located over the phenyl, ethyl and ether groups (Figure 7).

Chemical reactivity: The chemical reactivity parameters obtained for TAM drug are: ionization potential (I), which is defined as the energy needed to remove an electron from a molecule by $6.67 \mathrm{eV}$; electron affinity (EA), which measures the ability of a molecule to accept electrons or form anions upon $-0.56 \mathrm{eV}$; chemical hardness $(\eta)$, is the resistance to change its electronic configuration with $3.61 \mathrm{eV}$; electronegativity $(\chi)$, represents the tendency of atoms or molecules to attract electrons with $3.05 \mathrm{eV}$; electrophilicity index $(\omega)$, that gives an idea of the stabilization in energy when the system acquires electrons from the environment up to saturation by $1.29 \mathrm{eV}$; and chemical potential $(\mu)$, measures the tendency of electrons to be released from a system is $-3.05 \mathrm{eV}$. Which they were calculated using the molecular energies of the cationic, ionic and neutral species (Table 7). 
Table 6 The optimized geometrical parameters (Bond lengths $(\AA)$ and angles $\left(^{\circ}\right)$ and experimental of Tamoxifen

\begin{tabular}{|c|c|c|c|c|c|c|c|c|}
\hline \multicolumn{2}{|c|}{ Bond Lengths (A) } & \multirow{2}{*}{$\begin{array}{l}\text { X-Ray } \\
1.4\end{array}$} & \multirow{2}{*}{$\begin{array}{l}\text { M06/6-3 IG(d) } \\
.357\end{array}$} & \multicolumn{3}{|l|}{ Bond Angles $\left({ }^{\circ}\right)$} & \multirow{2}{*}{$\begin{array}{l}\text { X-Ray } \\
125.7\end{array}$} & \multirow{2}{*}{$\begin{array}{l}\text { M06/6-3 IG(d) } \\
118.165\end{array}$} \\
\hline 10 & $12 \mathrm{C}$ & & & $12 \mathrm{C}$ & 10 & $20 \mathrm{C}$ & & \\
\hline 10 & $20 \mathrm{C}$ & 1.477 & $1.4 \mathrm{II}$ & $19 \mathrm{C}$ & $2 \mathrm{~N}$ & $27 C$ & 114 & $|12.03|$ \\
\hline $2 \mathrm{~N}$ & $19 \mathrm{C}$ & 1.547 & 1.45 & $19 \mathrm{C}$ & $2 \mathrm{~N}$ & $28 \mathrm{C}$ & 112.6 & 110.377 \\
\hline $2 \mathrm{~N}$ & $27 C$ & 1.485 & 1.449 & $27 C$ & $2 \mathrm{~N}$ & $\mathrm{C} 28$ & 109.7 & 109.996 \\
\hline $2 \mathrm{~N}$ & $28 \mathrm{C}$ & 1.505 & 1.448 & $4 \mathrm{C}$ & $3 C$ & $5 C$ & 127.4 & 123.047 \\
\hline $3 C$ & $4 \mathrm{C}$ & 1.5 & 1.355 & $4 \mathrm{C}$ & $3 C$ & $7 C$ & 121.8 & 122.493 \\
\hline $3 C$ & $5 C$ & 1.605 & 1.485 & $5 C$ & $3 C$ & $7 C$ & 108.9 & II4.436 \\
\hline $3 C$ & $7 C$ & 1.525 & 1.487 & $3 C$ & $4 \mathrm{C}$ & $6 C$ & 127.4 & 123.667 \\
\hline $4 C$ & $6 C$ & 1.569 & 1.508 & $3 C$ & $4 \mathrm{C}$ & $8 C$ & 120.3 & $|22.08|$ \\
\hline $4 C$ & $8 C$ & 1.549 & 1.486 & $6 C$ & $4 \mathrm{C}$ & $8 C$ & 112.3 & 114.245 \\
\hline $5 C$ & $9 \mathrm{C}$ & 1.443 & 1.403 & $3 C$ & $5 C$ & $9 \mathrm{C}$ & 122.6 & 122.088 \\
\hline $5 C$ & $10 C$ & 1.457 & 1.396 & $3 C$ & $5 C$ & $10 \mathrm{C}$ & 119.7 & 120.368 \\
\hline $6 C$ & $I I C$ & 1.535 & 1.526 & $9 \mathrm{C}$ & $5 C$ & $10 C$ & 117.7 & 117.506 \\
\hline 7C & $15 \mathrm{C}$ & 1.452 & 1.4 & $4 C$ & $6 C$ & IIC & 115.2 & 113.054 \\
\hline $7 C$ & $16 C$ & 1.453 & 1.399 & $3 C$ & $7 C$ & $15 \mathrm{C}$ & 120.8 & 120.023 \\
\hline $8 C$ & $17 C$ & 1.436 & 1.399 & $3 C$ & $7 C$ & $16 C$ & 121 & 121.75 \\
\hline $8 C$ & $18 \mathrm{C}$ & 1.427 & 1.4 & $15 \mathrm{C}$ & $7 C$ & $16 C$ & 118.2 & 118.184 \\
\hline $9 \mathrm{C}$ & $13 C$ & 1.435 & 1.382 & $4 C$ & $8 C$ & I7C & 120.5 & 121.159 \\
\hline $10 \mathrm{C}$ & $14 \mathrm{C}$ & 1.406 & 1.391 & $4 C$ & $8 C$ & $18 \mathrm{C}$ & 120.1 & 120.602 \\
\hline $12 \mathrm{C}$ & $13 C$ & 1.454 & 1.398 & I7C & $8 C$ & $18 \mathrm{C}$ & 119.4 & 118.172 \\
\hline $12 \mathrm{C}$ & $14 \mathrm{C}$ & 1.46 & 1.394 & $5 C$ & $9 \mathrm{C}$ & $13 C$ & 121.7 & 121.323 \\
\hline $15 \mathrm{C}$ & $2 I C$ & 1.398 & 1.388 & $5 C$ & $10 \mathrm{C}$ & $14 \mathrm{C}$ & 121.9 & 121.947 \\
\hline $16 C$ & $22 C$ & 1.427 & 1.391 & 10 & $12 \mathrm{C}$ & $13 \mathrm{C}$ & II5.7 & $|15.96|$ \\
\hline I7C & $23 C$ & 1.414 & 1.39 & 10 & $12 \mathrm{C}$ & $14 \mathrm{C}$ & 125.3 & $124.5 \mid 8$ \\
\hline $18 \mathrm{C}$ & $24 C$ & 1.414 & 1.389 & $13 C$ & $12 \mathrm{C}$ & $14 C$ & 119 & 119.52 \\
\hline $20 \mathrm{C}$ & $19 \mathrm{C}$ & 1.529 & 1.514 & $9 \mathrm{C}$ & $13 C$ & $12 C$ & 119.5 & 120.248 \\
\hline $21 \mathrm{C}$ & $25 \mathrm{C}$ & 1.43 & 1.392 & $10 C$ & $14 C$ & $12 \mathrm{C}$ & 120.2 & $|19.44|$ \\
\hline $22 \mathrm{C}$ & $25 \mathrm{C}$ & 1.423 & 1.391 & $7 C$ & $15 \mathrm{C}$ & $21 \mathrm{C}$ & 121.3 & 120.954 \\
\hline $23 \mathrm{C}$ & $26 C$ & 1.419 & 1.391 & $7 C$ & $16 C$ & $22 \mathrm{C}$ & 119.9 & 120.967 \\
\hline \multirow[t]{10}{*}{$24 C$} & $26 C$ & 1.425 & 1.392 & $23 C$ & $17 C$ & $8 C$ & 120.5 & 120.952 \\
\hline & & & & $8 C$ & $18 \mathrm{C}$ & $24 C$ & 120 & 120.956 \\
\hline & & & & $2 \mathrm{~N}$ & $19 \mathrm{C}$ & $20 \mathrm{C}$ & III.I & 112.469 \\
\hline & & & & 10 & $20 \mathrm{C}$ & $19 \mathrm{C}$ & 111.6 & 106.643 \\
\hline & & & & $15 \mathrm{C}$ & $21 \mathrm{C}$ & $25 \mathrm{C}$ & 120 & 120.193 \\
\hline & & & & $16 C$ & $22 C$ & $25 \mathrm{C}$ & 120.2 & 120.145 \\
\hline & & & & I7C & $23 C$ & $26 C$ & 119.6 & 120.187 \\
\hline & & & & $18 \mathrm{C}$ & $24 C$ & $26 C$ & 120.2 & 120.229 \\
\hline & & & & $21 C$ & $25 \mathrm{C}$ & $22 \mathrm{C}$ & 120.4 & 119.54 \\
\hline & & & & $23 C$ & $26 C$ & $24 C$ & 120.4 & | | | \\
\hline
\end{tabular}


Table 7 Chemical reactivity parameters with M06/6-3IG (d)

\begin{tabular}{lllllll} 
Drug & \multicolumn{6}{l}{ Chemical reactivity descriptors } \\
\cline { 2 - 7 } TAM & $\mathrm{I}(\mathrm{eV})$ & $\mathrm{AE}(\mathrm{eV})$ & $\chi(\varepsilon \varsigma)$ & $\eta(\varepsilon \varsigma)$ & $\mu(\varepsilon \varsigma)$ & $\omega(\varepsilon \varsigma)$ \\
\cline { 2 - 7 } & 6.67 & -0.56 & 3.05 & $3.6 \mathrm{I}$ & -3.05 & -1.29
\end{tabular}

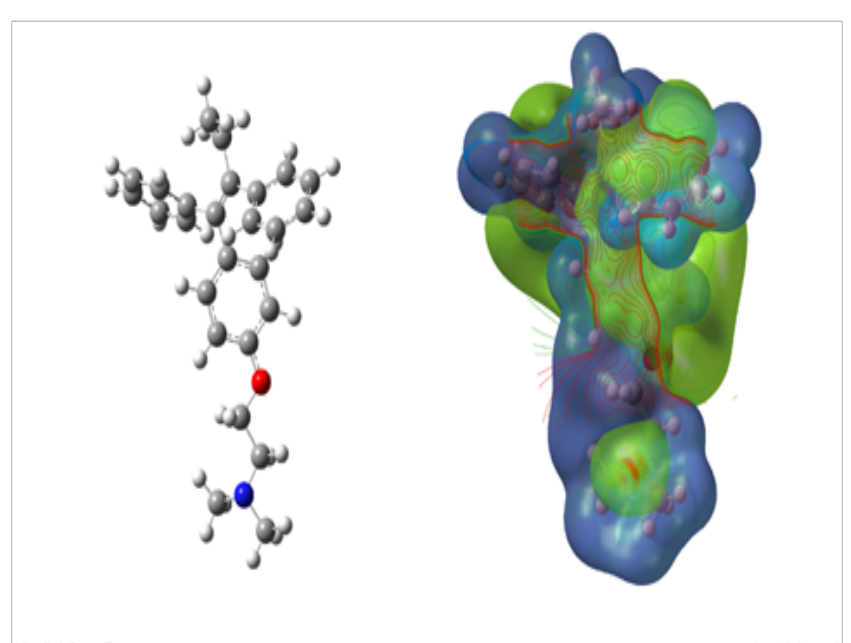

$-2.019 \mathrm{e}-2$

$1.469 e-2$

Figure 6 Optimized structure and calculated electrostatic potential map on the molecular surface for TAM drug calculated at the M06/6-3IG (d) level of theory. Color range oscillates $-2.019 \mathrm{e}-2$ to $1.469 \mathrm{e}-2$ : blue, more positive; red more negative.

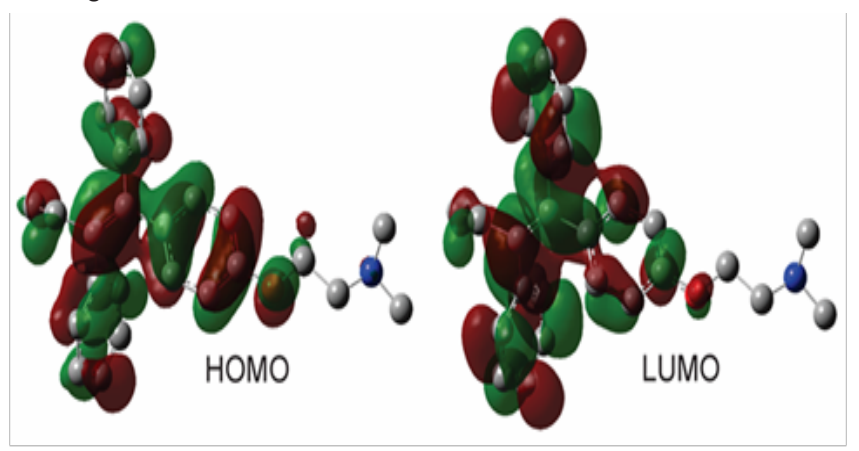

Figure 7 Molecular orbital's for TAM drug calculated at the M06/6-3 IG (d) level of theory.

\section{Conclusion}

In this work, different chemical models were implemented to determine the structural parameters and reactivity of TAM. The M06/6-31G (d) and PBE0/6-31G (d) chemical models had the best approach to the FT-IR spectrum for maximum absorption wavelengths the best results were obtained with M06/6-31G(d), PBE0/6-31G(d) and M05/6-31G(d). These chemical models yielded better results for modeling the structural parameters studied. The performed statistical analysis of the electron affinity and ionization potential reactivity parameters showed that has the closest approximation to the mean value is for M06/6-31G(d). Therefore, it was defined as the best methodology. The calculation of the structural parameters with this methodology was in good agreement with the experimental values and the electrostatic potential surface determined which moieties of the molecule will interact with the active site of the hormone receptor.

\section{Acknowledgements}

This work was supported by Consejo Nacional de Ciencia y
Tecnología (CONACYT) and Centro de Investigación en Materiales Avanzados, S.C. (CIMAV). LLLM gratefully acknowledge a fellowship from CONACYT. EOB is a researcher for CIMAV and CONACYT and NFH is a researcher of CIMAV and CONACYT.

\section{Conflict of interest}

The author declares no conflict of interest.

\section{References}

1. Altmeyer C, Karam TK, Khalil NM, et al. Tamoxifen-loaded poly (L-lactide) nanoparticles: Development, characterization and in vitro evaluation of cytotoxicity. Mater Sci Eng C Mater Biol Appl. 2016;60:135-142

2. Khan MM, Wakade C, de Sevilla L, et al. Selective estrogen receptor modulators (SERMs) enhance neurogenesis and spine density following focal cerebral ischemia. J Steroid Biochem Mol Biol. 2015;146:38-47.

3. Boyd DB, Coner RD. Stochastic approach to force field evaluations: conformational analysis of raloxifene, a potential new therapeutic agent for post-menopausal osteoporosis. J Mol Struc: THEOCHEM. 1996;368(1-3):7-15.

4. Jordan VC. Tamoxifen: a most unlikely pioneering. Nat Rev Drug Discov. 2003;2(3):205-213.

5. Maximov PY, Lee TM, Jordan VC. The Discovery and Development of Selective Estrogen Receptor Modulators (SERMs) for Clinical Practice. Curr Clin Pharmacol. 2013;8(2):135-155.

6. McDonnell DP, Wardell SE. The molecular mechanisms underlying the pharmacological actions of ER modulators: implications for new drug discovery in breast cancer. Curr Opin Pharmacol. 2010;10(6):620-628.

7. Kenawi IM. DFT analysis of diclofenac activity and cation type influence on the theoretical parameters of some diclofenac complexes. $J \mathrm{Mol}$ Struc: THEOCHEM. 2006;761(1-3):151-157.

8. Flores HN, Glossman MD. CHIH-DFT determination of the electrical, optical, and magnetic properties and NICS aromaticity of megazol. $J$ Mol Struc: THEOCHEM. 2005;717(1-3):1-3.

9. De Benedetti PG, Quartieri S, Rastelli A. A theoretical study of the structure-activity relationship in sulpha drugs. J Mol Struc: THEOCHEM. 1981;85(1-2):45-51.

10. Luzhkov VB. Electronic parameters and molecular mechanisms of biological action of nitroxyl radicals. J Mol Struc: THEOCHEM. 1985; 121:165-172.

11. Shankar Rao YB, Prasad MVS, Udaya Sri N, et al. Vibrational (FTIR, FT-Raman) and UV-Visible spectroscopic studies, HOMOLUMO, NBO, NLO and MEP analysis of Benzyl (imino $(1 \mathrm{H}-$ pyrazol-1-yl) methyl) carbamate using DFT calculaions. J Mol Struct. 2016;1108:567-582.

12. Fang H, Tong W, Shi LM, et al. Structure-Activity Relationships for a Large Diverse Set of Natural, Synthetic, and Environmental Estrogens. Chem Res Toxicol. 2001;14(3):280-294.

13. Maximov PY, Myers CB, Curpan RF, et al. Structure-Function Relationships of Estrogenic Triphenylethylenes Related to Endoxifen and 4-Hydroxytamoxifen. J Med Chem. 2010;53(8):3273-3283. 
14. Karabacak M, Kose E, Sas EB, et al. DFT calculations and experimental FT-IR, FT-Raman, NMR, UV-Vis spectral studies of 3-fluorophenylboronic acid. Spectrochim Acta A Mol Biomol Spectrosc. 2015;136(Part B):306-320.

15. Rigol C, Olea AC, Mendizabal F, et al. Theoretical study on 5-nitrofuryl thiosemicarbazone radicals electronic properties. J Mol Struc: THEOCHEM. 2006;770(1-3):125-129.

16. Hazarika KK, Baruah NC, Deka RC. Molecular structure and reactivity of antituberculosis drug molecules isoniazid, pyrazinamide, and 2-methylheptylisonicotinate: a density functional approach. Struct Chem. 2009;20(6):1079-1085.

17. Gao L, Tu Y, Wegman P, et al. Conformational Enantiomerization and Estrogen Receptor $\alpha$ Binding of Anti-Cancer Drug Tamoxifen and Its Derivatives. J Chem Inf Model. 2011;51(2):306-314.

18. Wang Y, Liu Q, Qiu L, et al. Molecular structure, IR spectra, and chemical reactivity of cisplatin and transplatin: DFT studies, basis set effect and solvent effect. Spectrochim Acta A Mol Biomol Spectrosc. 2015;150:902-908.

19. Mansour AM. Coordination behavior of sulfamethazine drug towards $\mathrm{Ru}(\mathrm{III})$ and $\mathrm{Pt}(\mathrm{II})$ ions: Synthesis, spectral, DFT, magnetic, electrochemical and biological activity studies. Inorg Chim Acta. 2013;394:436445 .

20. Behera S, Subhajit G, Ahmad F, et al. UV-Visible Spectrophotometric Method Development and Validation of Assay of Paracetamol Tablet Formulation. J Anal Bioanal Tech. 2012;3(6):1-6.

21. Rassolov VA, Ranter MA, Pople JA, et al. 6-31G* Basis Set for ThirdRow Atoms. J Comput Chem. 2001;22(9):976-984.

22. Flores-Holguin N, Glossman-Mitnik D. CHIH-DFT determination of the molecular structure, infrared and ultraviolet spectra of the antiparasitic drug megazol. J Mol Struc: THEOCHEM. 2004;681(1-3):77-82.

23. Sanchez BNA, Flores HN, Glossman-Mitnik D, et al. Computational note on the chemical reactivity of pyrrole derivatives. J Mol Struc: THEOCHEM. 2009;912(1-3):119-120.

24. Sanchez-Bojorge NA, Rodriguez-Valdez L-M, Glossman-Mitnik D, et al. Theoretical calculation of the maximum absorption wavelength for Cyanidin molecules with several methodologies. Comput Theor Chem. 2015;1067:129-134.

25. Shukla VK, Sachan AK, Pathak SK, et al. Prediction of molecular properties and spectroscopic profile of Riluzole with different functionals (B3LYP, M06-2X, MPWLYP):A combined theoretical and experimental study. J Mol Struct. 2016;1106:265-276.

26. Soto RR, Baldenebro LJ, Glossman MD. Study of chemical reactivity in relation to experimental parameters of efficiency in coumarin derivatives for dye sensitized solar cells using DFT. Phys Chem Chem Phys. 2015;17(21):14122-14129.

27. Gaussian 09 [computer program]. Wallingford, CT. USA: Gaussian Inc; 2009.

28. Kohn W, Hohenbergt P. Inhomogeneous Electron Gas. Phys Rev. 1964;136(3B):B864-B871.

29. Kohn W, Sham LJ. Self-Consistent Equations Including Exchange and Correlation Effects. Phys Rev. 1965;140(4A):A1133-A1138.

30. Robert G Parr, Weitao Y. Density-Functional Theory of Atoms and Molecules. USA: Oxford University Press; 1989.

31. Lopez JM, Ensuncho AE, Robles JR. Descriptores globales y locales de la reactividad para el diseño de nuevos fármacos anticancerosos basados en Cis-platino (II). Quim Nova. 2013;36(9):1308-1317.
32. Hariharan PC, Peoble JA. Accury of AH equilibrium geometries by single determinant molecular orbital theory. Theor Chim Acta. 1973;28:213.

33. Becke AD. Density-functional thermochemistry. III. The role of exact exchange. J Chem Phys. 1993;98(7):5648-5652.

34. Perdew JP, Burke K, Ernzerhof M. Generalized Gradient Approximation Made Simple. Phys Rev Lett. 1997;77(18):3865-3868.

35. Tao J, Perdew JP, Staroverov VN, et al. Climbing the Density Functional Ladder: Nonempirical Meta-Generalized Gradient Approximation Designed for Molecules and Solids. Phys Rev Lett. 2003;91(14):146401.

36. Zhao Y, Trulhar DG. A new local density functional for main-group thermo chemistry, transition metal bonding, thermochemical kinetics, and noncovalent interactions. JJ Chem Phys. 2006;125(19):194101.

37. Zhao Y, Schultz N, Truhlar DG. Design of density functionals by combining the method of constraint satisfaction with parametrization for thermochemistry, thermochemical kinetics, and noncovalent interactions. \J Chem Theory Comput. 2006;2(2):364-382.

38. Zhao Y, Truhlar DG. Density functionals with broad applicability in chemistry. Acc Chem Res. 2008;41(2):157-167.

39. Zhao Y, Schultz N, Truhlar DG. Exchange-correlation functional with broad accuracy for metallic and non-metallic compounds, kinetics, and noncovalent interactions. ¡J Chem Phys. 2005;123(16):161103.

40. Zhao Y, Trulhar DG. The M06 suite of density functionals for main group thermo chemistry, thermo chemical kinetics, noncovalent interactions, excited states, and transition elements: two new functionals and systematic testing of four M06-class functionals and 12 other functionals. Theor Chem Acc. 2008;120(1-3):215-241.

41. Zhao Y, Trulhar DG. Density functional for spectroscopy: no long-range self-interaction error, good performance for Rydberg and chargetransfer states, and better performance on average than B3LYP for ground states. J Phys Chem A. 2006;110(49):13126-13130.

42. Burke K, Werschnik J, Gross EKU. Time-dependent density functional theory: Past, present, and future. J Chem Phys. 2005;123(6):062206.

43. Stratmann RE, Scuseria GE, Frisch MJ. An efficient implementation of time-dependent density-functional theory for the calculation of excitation energies of large molecules. J Chem Phys. 1998;109(19):82188224.

44. Bauernschmitt R, Ahlrichs R. Treatment of electronic excitations within the adiabatic approximation of time dependent density functional theory. Them Phys Lett. 1996;256(4-5):454-464.

45. "Swizard program" [computer program]. Canada: University of Ottawa; 2012.

46. Barone V, Cossi M. Quantum Calculation of Molecular Energies and Energy Gradients in Solution by a Conductor Solvent Model. J Phys Chem A. 1998;102(11):1995-2001.

47. Takano Y, Houk KN. Benchmarking the Conductor-like Polarizable Continuum Model (CPCM) for Aqueous Solvation Free Energies of Neutral and Ionic Organic Molecules. J Chem Theory Comput. 2005;1(1):70-77.

48. Frisch JB, AEleen Frisch. Exploring Chemistry with Electronic Structure Methods. Gaussian Inc. 2nd ed. Pittsburgh, Pennsylvania; 1996. $171 \mathrm{p}$.

49. Lewars E. Computational Chemistry: Introduction to the Theory and Applications of Molecular and Quantum Mechanics. Massachusetts, USA; 2003.

50. Pearson RG. Absolute electronegativity and hardness correlated with molecular orbital theory. Proc Natl Acad Sci USA. 1986;83(22):84408441 . 
51. Putz MV, Russo N, Sicilia E. Atomic Radii Scale and Related Size Properties from Density Functional Electronegativity Formulation. J Phys Chem A. 2003;107(28):5461-5465.

52. Parr RG, Donnelly RA, Levy M, et al. Electronegativity: The density functional viewpoint. J Chem Phys. 1978;68(8):3801-3807.

53. Parr RG, Szentpaly Lv, Liu S. Electrophilicity Index. J Am Chem Soc. 1999;121(9):1922-1924.

54. Shakourian FM, Jamshidi Z, Kamath G. Surface Charge-Transfer Doping of Graphene Nanoflakes Containing Double-Vacancy (5-8-5) and Stone-Wales (55-77) Defects through Molecular Adsorption. Chem phys chem. 2016;17(20):3289-3299.

55. Shakourian-Fard M, Kamath G. The effect of defect types on the electronic and optical properties of graphene nanoflakes physisorbed by ionic liquids. Phys Chem Chem Phys. 2017;19(6):4383-4395.

56. Upadhyay SU, Patel VA, Patel JK, et al. Fabrication of solid lipid nanoparticles containing tamoxifen citrate and impact of process parameters on formulation. Int J Biol Phar Res. 2012;3:422-430.
57. Merey HA, Galal MM, Salem MY, et al. Novel stability indicating methods for the determination of certain synthetic estrogen level modifiers. Bull Fac Pharm Cairo Univ. 2013;51(1):69-79.

58. Burke $\mathrm{K} \&$ friends. The ABC of DFT. USA: University of California; 2007. p. $1-104$

59. Garrido J, Quezada E, Fajin J, et al. Electrochemical oxidation of tamoxifen revisited. Int J Electrochem Sci. 2013;8(4):5710-5723.

60. Baldenebro LJ, Castorena GJ, Flores HN, et al. Computational Molecular Nanoscience Study of the Properties of Copper Complexes for Dye-Sensitized Solar Cells. Int J Mol Sci. 2012;13(12):16005-16019.

61. Fitz GCT, Morris LL. How to Analyze Data. USA: Sage Publications Inc; 1987.

62. PDB Chemical Component CTX. 2016.

63. Morrison RT, Boyd RN. Quimica organica. UK: Pearson Educacion; 1998. 